\title{
BMJ
}

\section{Exercise on prescription for women aged 40-74 recruited through primary care: two year randomised controlled trial}

\author{
Beverley A Lawton, director, ${ }^{1}$ Sally B Rose, research fellow, ${ }^{1}$ C Raina Elley, senior lecturer , ${ }^{2}$ \\ Anthony C Dowell, professor, ${ }^{3}$ Anna Fenton, endocrinologist, ${ }^{4}$ Simon A Moyes, biostatistician ${ }^{2}$
}

'Women's Health Research Centre, Department of Primary Health Care and General Practice, PO Box 7343, University of Otago, Wellington, New Zealand

${ }^{2}$ Department of General Practice and Primary Health Care, School of Population Health, University of Auckland, Private Bag 92019,

Auckland, New Zealand

${ }^{3}$ Department of Primary Health Care and General Practice, PO Box 7343, University of Otago, Wellington, New Zealand

${ }^{4}$ Christchurch Women's Hospital, Christchurch, New Zealand

Correspondence to: B Lawton

Bev.Lawton@otago.ac.nz

Cite this as: BMJ 2008;337:a2509 doi:10.1136/bmi.a2509

\section{ABSTRACT}

Objective To assess the effectiveness of a primary care based programme of exercise on prescription among relatively inactive women over a two year period.

Design Randomised controlled trial.

Setting 17 primary care practices in Wellington, New Zealand

Participants 1089 women aged 40-74 not undertaking 30 minutes of moderate intensity physical activity on at least five days of the week

Intervention Brief physical activity intervention led by nurse with six month follow-up visit and monthly telephone support over nine months.

Main outcome measure Physical activity assessed at baseline and 12 and 24 months. Secondary outcomes were quality of life (SF-36), weight, waist circumference, blood pressure, concentrations of fasting serum lipids, glycated haemoglobin $\left(\mathrm{HbA}_{1 \mathrm{c}}\right)$, glucose, insulin, and physical fitness.

Results Mean age was 58.9 (SD 7) years. Trial retention rates were $93 \%$ and $89 \%$ at 12 and 24 months, respectively. At baseline, $10 \%$ of intervention participants and $11 \%$ of control participants were achieving 150 minutes of at least moderate intensity physical activity a week. At 12 months rates increased to $43 \%$ and $30 \%$ and at 24 months to $39.3 \%$ and $32.8 \%$ ( $\mathrm{P}<0.001)$, respectively. SF-36 physical functioning $(\mathrm{P}=0.03)$ and mental health ( $\mathrm{P}<0.05)$ scores improved more in intervention compared with control participants, but role physical scores were significantly lower $(\mathrm{P}<0.01)$. There were no significant differences in clinical outcomes. More falls $(P<0.001)$ and injuries $(P=0.03)$ were recorded in the intervention group.

Conclusions This programme of exercise on prescription increased physical activity and quality of life over two years, although falls and injuries also increased. This finding supports the use of exercise on prescription programmes as part of population strategies to reduce physical inactivity.

Trial registration Australian New Zealand Clinical Trials Registry (ANZCTR) ANZCTRN012605000490673.

\section{INTRODUCTION}

Physical inactivity is a major contributor to chronic disease, including ischaemic heart disease, stroke, breast cancer, colon cancer, and type 1 diabetes. ${ }^{1-4}$ The United Kingdom government has set a target for $70 \%$ of the population to be active by $2020^{1}$ - that is, 30 minutes of moderate intensity physical activity five times a week, as recommended by the US Surgeon General in $1996 .{ }^{5}$ Currently, only $40 \%$ of men and $28 \%$ of women in the UK are meeting this target, ${ }^{6}$ with similar proportions among adults in New Zealand. ${ }^{7}$ Although it is widely recognised that population increases in physical activity would have important public health benefit, few long term evaluations of physical activity interventions have shown improvements in clinical risk indices with increases in physical activity. Secondary prevention studies have shown that lifestyle interventions can prevent progression to diabetes, ${ }^{8-10}$ but these studies used interventions that were too intensive and expensive to be practical from a population perspective. Studies evaluating strategies to promote physical activity in general populations have often had methodological limitations including lack of randomisation or control groups, short duration, extensive screening and exclusion criteria, and failure to blind assessors to treatment allocation. ${ }^{11}$

"Exercise on prescription" interventions that involve a health professional's written advice to a patient to be more physically active have been used with variable success. ${ }^{12} 13$ The "green prescription" programme, which is widely implemented throughout primary care in New Zealand, has been shown to produce significant improvements in levels of physical activity and quality of life among "relatively inactive" (not undertaking the recommended 30 minutes on at least five days of the week) adults aged 40-79 in primary care over a 12 month period. ${ }^{14}$ The green prescription intervention is cost effective ${ }^{1516}$ and produced a $10 \%$ incremental increase in adherence to physical activity among those receiving the intervention compared with the control group. Although changes in clinical indices were not statistically significant, there were trends towards reduced systolic and diastolic blood pressure and total cholesterol concentrations, which were potentially clinically significant. ${ }^{17}$ It was not known, however, how long the increase in physical activity would be sustained past one year. We used a randomised controlled trial design to test the 


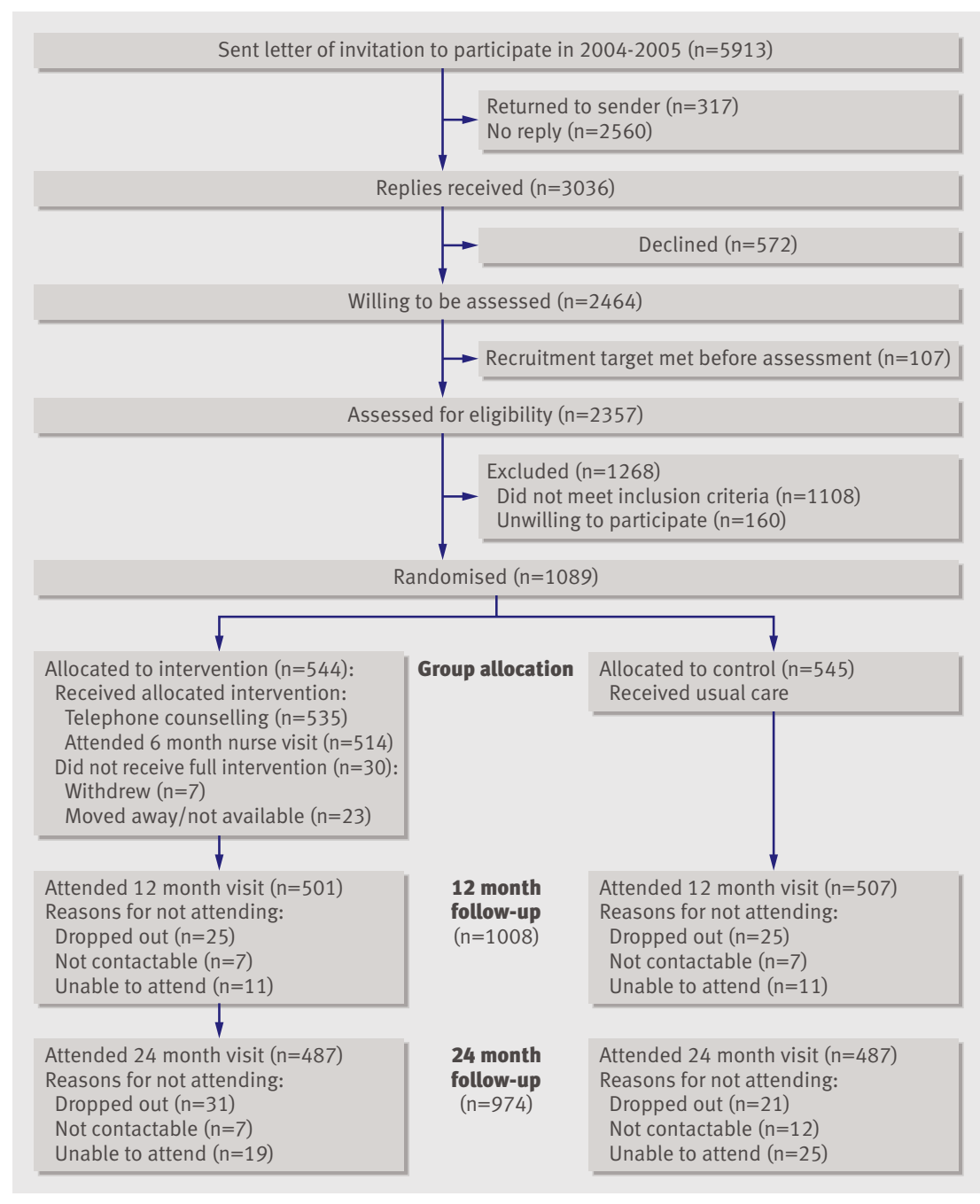

Fig 1| Recruitment and retention of participants
Participants were recruited from two sources. The first source was an existing cohort of 50-74 year old women recruited by invitation letter from their general practitioner to a previous observational study of postmenopausal women between 1999 and 2002 from 10 primary care practices in Wellington. ${ }^{21}$ The remainder of the participants were 50-70 year old women (40-60 years for Maori and Pacific women) recruited from 13 primary care practices in 2004-5, including two Maori health clinics. General practitioners at participating practices were asked to identify women in the age group from their practice register, excluding patients deemed inappropriate for participation in a physical activity trial. The general practitioners sent letters to those identified as suitable, inviting them to participate in a lifestyle study. The invitation letter requested that women contact the research team if they were interested in learning more about the study using the reply slip and prepaid envelope supplied. A research nurse telephoned those who replied to determine eligibility and to invite them to an interview. Interviews were held at one of six community healthcare settings. ${ }^{22}$

\section{Outcome measures}

Our primary outcome measure was the proportion of those achieving the recommended 150 minutes of at least moderate intensity physical activity, as assessed by the long form of the physical activity questionnaire. This self reported questionnaire asks participants about physical activity carried out in the past seven days in relation to activity type, context, intensity, and duration. It has been validated against an objective measure of energy expenditure (heart rate monitoring) and self reported physical activity logs and against the validated international physical activity questionnaire (IPAQLong) $)^{23}$ in a study of 186 adults. ${ }^{2425}$

Secondary outcomes included quality of life assessed with the short form 36 questionnaire (SF-36) ${ }^{26}$; weight, waist circumference, and blood pressure, recorded by trained research nurses at each visit; and concentrations of fasting serum lipids, glycated haemoglobin $\left(\mathrm{HbA}_{1 \mathrm{c}}\right)$, glucose, and insulin, measured from blood samples tested at one laboratory accredited by International Accreditation New Zealand (IANZ). Physical fitness was measured with a three minute step test. Twelve month recall of falls and injuries was monitored for adverse events. Outcome measures were assessed at baseline, 12 months, and 24 months. Demographic characteristics and information about medical conditions and current medications were collected at each assessment.

\section{Randomisation and blinding}

A researcher not involved in the recruitment process carried out computer generated block randomisation. We maintained allocation concealment until after we obtained written consent and completed baseline measures. After baseline measures the nurse opened sequentially numbered opaque envelopes containing the allocated treatment group (intervention or control).
Participants were excluded if they had a medical condition that might be adversely affected by increasing their physical activity, as determined by the physical activity readiness questionnaire (PAR-Q $)^{20}$ and subsequent assessment by their own general practitioner. 
Nurses assessing participants at 12 and 24 month follow-up visits were blind to group allocation, and participants were asked not to discuss group allocation with the assessing nurse.

\section{Intervention}

The intervention we assessed was built on an existing primary care programme, the green prescription, in which the general practitioner or practice nurse briefly counsels (7-13 minutes) patients using motivational interviewing techniques to increase physical activity among those who are physically inactive. The details of the exercise advice are written on a "green script," which is given to the patient and faxed to a community based exercise facilitator who provides telephone support over a three month period, assisting with choice of activity, goal setting, and ways to overcome personal barriers to physical activity. ${ }^{1427}$ In our study a primary care nurse delivered the green prescription and follow-up was extended to include telephone calls over a nine month period (average of five calls, each lasting 15 minutes) with an added 30 minute visit with the primary care nurse at six months. The recommended goal was moderate intensity physical activity such as brisk walking, with a goal of achieving 30 minutes five days a week. The nurse noted clinical details including weight, height, waist circumference, smoking status, and any relevant medical conditions on the faxed script.

During the visit at six months the nurse established whether the participant had increased her physical activity to the target level, provided encouragement and motivation, and measured blood pressure, weight, and waist circumference. Tools to assist with choosing appropriate types of activities and motivational aids, such as fridge magnets and activity record charts, were also offered. Further details about the intervention are

\begin{tabular}{|c|c|c|}
\hline Characteristic & Intervention $(n=544)$ & Control $(n=545)$ \\
\hline Age (years) & $59.1(6.8)$ & $58.7(6.9)$ \\
\hline Body mass index & $29.2(5.8)$ & $29.2(6.1)$ \\
\hline Leisure exercise/week (mins) & $58(84)$ & $60(91)$ \\
\hline \multicolumn{3}{|l|}{ Quality of life (SF-36): } \\
\hline Role physical & $90.4(18.7)$ & $89.8(14.4)$ \\
\hline Bodily pain & $72.0(23.0)$ & $74.2(23.3)$ \\
\hline Vitality & $59.0(14.2)$ & $59.5(13.5)$ \\
\hline Social functioning & $89.2(18.2)$ & $89.2(18.3)$ \\
\hline Role emotional & $92.2(16.5)$ & $93.4(14.3)$ \\
\hline Mental health & $71.2(11.9)$ & $71.7(10.6)$ \\
\hline General health & $76.4(17.9)$ & $78.0(17.9)$ \\
\hline \multicolumn{3}{|l|}{ No (\%) of participants: } \\
\hline Current smokers & $67(12)$ & 70 (13) \\
\hline Lower socioeconomic status $^{29}$ & $87(16)$ & 75 (14) \\
\hline With tertiary education & $230(42)$ & $246(45)$ \\
\hline European & $411(76)$ & $435(80)$ \\
\hline Maori or Pacific Islander & 79 (15) & $64(12)$ \\
\hline
\end{tabular}

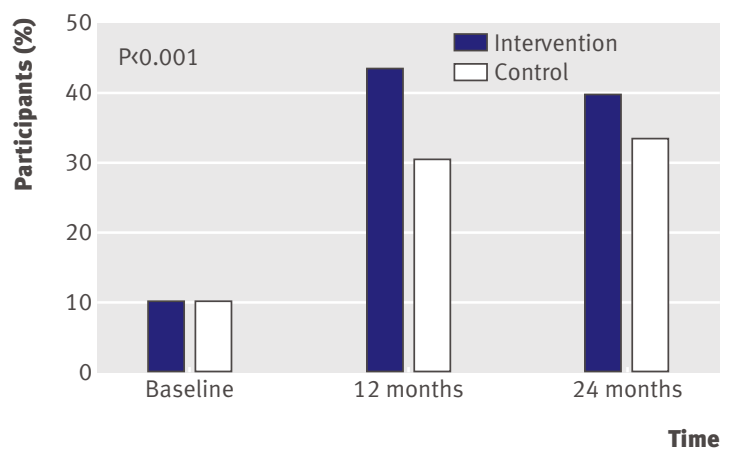

$\overline{\text { Fig } 2 \text { | Proportion of participants achieving at least } 150 \text { minutes }}$ of moderate intensity physical activity at baseline and 12 and 24 months

available elsewhere. ${ }^{22}$ Control participants received usual care from their primary care practice.

\section{Sample size calculation}

Based on means, standard deviations, and levels of physical activity achieved in previous trials, we calculated we needed a sample size of 880 to detect a minimum difference between the groups of $7 \%$ change in the proportion of women reaching the target level of 150 minutes of at least moderate intensity physical activity each week, allowing for a $10 \%$ attrition rate $\left(\alpha=0.05,80 \%\right.$ power). ${ }^{1428}$ This sample size was adequate to detect as significant, a difference between the groups in secondary outcomes of $3 \mathrm{~mm} \mathrm{Hg}$ diastolic blood pressure, $4 \mathrm{~mm} \mathrm{Hg}$ systolic blood pressure, $0.25 \mathrm{mmol} / \mathrm{l}$ serum cholesterol, $0.1 \mathrm{mmol} / \mathrm{l}$ high density lipoprotein cholesterol, and $0.2 \% \mathrm{HbA}_{1 \mathrm{c}}$.

\section{Statistical analyses}

We carried out an intention to treat analysis of all participants enrolled in the study according to allocation of randomisation, regardless of adherence to physical activity. For missing data at follow-up assessments, we assumed no change from baseline. Final analyses were undertaken with regression models, adjusted for repeated measures and baseline values, in SAS version 9.2. Non-normally distributed data were log transformed.

\section{RESULTS}

We recruited participants from 17 primary healthcare practices in Wellington and in 2004-5 enrolled 1089 less active women. Figure 1 shows the progression of participants through the trial. Characteristics of the study participants were balanced at baseline (tables 1 and 2). Trial retention rates were $93 \%$ and $89 \%$ at 12 and 24 months, respectively.

Both groups increased their physical activity over the two years. Mean physical activity levels, however, were higher $(\mathrm{P}=0.01)$ and a greater proportion reached the target of 150 minutes of at least moderate intensity physical activity in the intervention group compared with the control group at 12 months (233 (43\%) v 165 $(30 \%), \quad(\mathrm{P}<0.001)$, with levels declining but still 
Table 2 |Primary and secondary clinical outcome measures and adverse events in intervention and control groups at baseline and 12 and 24 months. Values are means (SD) unless stated otherwise

\begin{tabular}{|c|c|c|c|}
\hline Outcome measures & Intervention $(n=544)$ & Control $(n=545)$ & P value* \\
\hline \multicolumn{4}{|l|}{ Primary } \\
\hline \multicolumn{4}{|c|}{ No (\%) completing at least 150 minutes physical activity/week: } \\
\hline Baseline & $56(10)$ & $62(11)$ & \multirow{3}{*}{$<0.001$} \\
\hline 12 months & $233(43)$ & $165(30)$ & \\
\hline 24 months & 214 (39) & $179(33)$ & \\
\hline \multicolumn{4}{|c|}{ Median (interquartile range) minutes physical activity/week: } \\
\hline Baseline & $30(0-90)$ & $30(0-90)$ & \multirow{3}{*}{$0.01 \dagger$} \\
\hline 12 months & $120(0-210)$ & $75(0-170)$ & \\
\hline 24 months & $105(0-205)$ & $90(0-190)$ & \\
\hline
\end{tabular}

\section{Secondary}

Systolic blood pressure $(\mathrm{mm} \mathrm{Hg})$ :

\begin{tabular}{|c|c|c|c|}
\hline Baseline & $122.8(0.7)$ & $123.4(0.8)$ & \multirow{3}{*}{0.50} \\
\hline 12 months & $120.6(0.7)$ & $121.9(0.7)$ & \\
\hline 24 months & $119.1(0.7)$ & $119.5(0.7)$ & \\
\hline \multicolumn{4}{|c|}{ Diastolic blood pressure $(\mathrm{mm} \mathrm{Hg})$ : } \\
\hline Baseline & $73.8(0.4)$ & $74.7(0.4)$ & \multirow{3}{*}{0.96} \\
\hline 12 months & $71.5(0.4)$ & $72.4(0.4)$ & \\
\hline 24 months & $71.6(0.4)$ & $71.7(0.4)$ & \\
\hline \multicolumn{4}{|l|}{ Weight (kg): } \\
\hline Baseline & $73.2(0.6)$ & $72.7(0.6)$ & \multirow{3}{*}{0.60} \\
\hline 12 months & $72.6(0.6)$ & $72.7(0.6)$ & \\
\hline 24 months & $72.6(0.6)$ & $72.5(0.6)$ & \\
\hline \multicolumn{4}{|c|}{ Waist circumference $(\mathrm{cm})$ : } \\
\hline Baseline & $86.7(0.6)$ & $86.2(0.6)$ & \multirow{3}{*}{0.70} \\
\hline 12 months & $87.3(0.5)$ & $87.3(0.5)$ & \\
\hline 24 months & $88.7(0.6)$ & $88.7(0.6)$ & \\
\hline \multicolumn{4}{|c|}{ Cholesterol (mmol/l): } \\
\hline Baseline & $6.10(0.05)$ & $6.03(0.05)$ & \multirow{3}{*}{0.90} \\
\hline 12 months & $5.86(0.04)$ & $5.83(0.04)$ & \\
\hline 24 months & $5.65(0.04)$ & $5.59(0.04)$ & \\
\hline
\end{tabular}

High density lipoprotein cholesterol $(\mathrm{mmol} / \mathrm{l})$ :

\begin{tabular}{|c|c|c|c|}
\hline Baseline & $1.65(0.02)$ & $1.63(0.02)$ & \multirow{3}{*}{0.40} \\
\hline 12 months & $1.73(0.02)$ & $1.71(0.02)$ & \\
\hline 24 months & $1.66(0.02)$ & $1.66(0.02)$ & \\
\hline \multicolumn{4}{|l|}{$\mathrm{HbA}_{1 \mathrm{c}}(\%):$} \\
\hline Baseline & $5.55(0.02)$ & $5.46(0.03)$ & \multirow{3}{*}{0.60} \\
\hline 12 months & $5.70(0.02)$ & $5.61(0.02)$ & \\
\hline 24 months & $5.74(0.02)$ & $5.69(0.02)$ & \\
\hline \multicolumn{4}{|c|}{ Insulin (pmol/l): } \\
\hline Baseline & $41.3(1.2)$ & $41.0(1.2)$ & \multirow{3}{*}{0.70} \\
\hline 12 months & $45.8(1.2)$ & $46.7(1.3)$ & \\
\hline 24 months & $48.6(1.3)$ & $48.4(1.3)$ & \\
\hline \multicolumn{4}{|c|}{ Glucose $(\mathrm{mmol} / \mathrm{l})$ : } \\
\hline Baseline & $5.02(0.03)$ & $4.96(0.02)$ & \multirow{3}{*}{0.99} \\
\hline 12 months & $4.97(0.03)$ & $4.96(0.03)$ & \\
\hline 24 months & $4.92(0.03)$ & $4.87(0.02)$ & \\
\hline
\end{tabular}

\section{Adverse events}

No (\%) of falls:

\begin{tabular}{|c|c|c|c|}
\hline Baseline & $138(25)$ & $155(29)$ & \multirow{3}{*}{$<0.001$} \\
\hline 12 months & $158(32)$ & $127(25)$ & \\
\hline 24 months & $179(37)$ & $143(29)$ & \\
\hline \multicolumn{4}{|c|}{ No (\%) of injuries: } \\
\hline Baseline & 77 (14) & $103(19)$ & \multirow{3}{*}{0.03} \\
\hline 12 months & 91 (18) & $86(17)$ & \\
\hline 24 months & $92(19)$ & 66 (14) & \\
\hline
\end{tabular}

*Analyses took into account repeated measures and adjusted for baseline values. Data that were not normally distributed were log transformed.

†Significance calculated after log transformation of data because of skewed nature of data. significantly different at two years (214 (39\%) $v 179$ (33\%), fig 2 and table 2). SF-36 physical functioning $(\mathrm{P}=0.03)$ and mental health $(\mathrm{P}<0.05)$ subscores were also significantly better in the intervention group at 12 and 24 months, although role physical scores were lower in the intervention group $(\mathrm{P}<0.01)$ (table 3$)$. There were no significant differences between groups in any of the secondary clinical outcomes (table 2). There was also no significant difference in the proportions on antihypertensive $(\mathrm{P}=0.90)$ or lipid lowering $(\mathrm{P}=0.80)$ drugs between the groups over the two years. Adjustment for medication did not significantly change the results on blood pressure and lipid outcome in sensitivity analyses. More falls $(\mathrm{P}<0.001)$ and injuries $(\mathrm{P}=0.03)$ were recorded in the intervention group compared with the control group over the two years (table 2). We deviated from planned analyses in the omission of data relating to physical fitness (a secondary outcome) as the potential for inaccuracies in the recording of pulse rate meant the quality of the data was questionable and not analysed here.

Although a large proportion of control participants increased their physical activity during the trial, only $2.4 \%$ (11/480 women contacted) recalled having received a green prescription from their doctor or nurse during the data collection period.

\section{DISCUSSION}

Exercise on prescription can increase physical activity and improve some variables of quality of life over two years among physically inactive women recruited through primary care compared with usual care. In our study, however, the increased levels of physical activity did not produce significant improvements in clinical or biochemical variables, and there were increases in falls and injuries and a reduction in the SF-36 role physical score.

The increases in physical activity were most marked at 12 months. We expected deterioration over time in physical activity after 12 months and, although levels had declined by 24 months, they were still substantially higher than at baseline and significantly higher in the intervention group than in the control group.

\section{Comparison with other studies}

The two year follow-up makes this study one of the first primary prevention physical activity trials to show a significant effect of physical activity counselling over two years. The activity counselling trial compared two behavioural counselling approaches of different intensities (intervention arms) with brief advice from a physician and written materials (control arm). The intensive interventions produced more improvement in cardiorespiratory fitness in women but not men over two years, but there was no change in self reported physical activity in men or women. ${ }^{30}$ However, there was no true control group. The activity counselling trial also assessed adverse events and found that each year about 30\% sustained a musculoskeletal event after the intervention in all three groups, which was higher than 
the rate of injury in either group in our trial, although the rate of falls in our trial was about $30 \%$.

The recently reported "ProActive" randomised controlled trial in primary care involved adults with a family history of diabetes who were randomised to a one year behaviour change programme (delivered by telephone or face to face) or to a control group (given an advice leaflet on physical activity). ${ }^{31}$ At one year, daytime physical activity had improved in both groups, but there were no significant differences between them. Similar to the present study, the ProActive trial showed improvements on some measures of quality of life but no improvements in clinical variables. ${ }^{31}$ The positive impact of physical activity on quality of life, in addition to cardiovascular benefits, has been well documented and is associated with positive health outcomes. ${ }^{32} 33$

The incremental increase in physical activity in our study was more than was found with the briefer green prescription intervention over one year $(12.5 \%$ v $10 \%$ at 12 months) and similar improvements were observed in quality of life variables. ${ }^{14}$ In the earlier green prescription trial, participants indicated that more follow-up with health professionals might help with adherence to physical activity. ${ }^{14}$ The current intervention provided this extended follow-up.

\section{Strengths and limitations}

The strengths of this study include the large sample size, the inclusion of a representative sample of ethnic minorities (Maori and Pacific people), high retention rates at two years (89\%), and blinding of outcome assessment. Adverse events were monitored and cost variables were collected for subsequent analysis of cost effectiveness. The intervention could be used beyond the research setting as the simple version of the green prescription is already disseminated widely throughout primary care in New Zealand; in 2007, 87\% of general practitioners issued a green script and over 20000 patients were supported nationally. ${ }^{34}$ Furthermore, the use of a simple and validated question to identify inactive patients ${ }^{19}$ can also be used in everyday primary care to identify those who would benefit from a physical activity intervention.

Limitations of this study include the inability to blind participants to the intervention. Participants in both groups showed a high uptake of physical activity. This positive effect in the control group might have reflected a trend in the population, participation in a study about physical activity, or the fact that those who agreed to take part in a trial were more motivated to change anyway than those who declined. Furthermore, the time spent with the research nurse at each assessment might have acted as an intervention in itself. Contamination is unlikely as few participants in the control group reported having received a green prescription (the basic version of the intervention used) during the study.

Although participants were recruited through primary care, their participation was by special invitation and the delivery of the intervention was not part of routine care. Even so, the basic green prescription is already part of routine care in New Zealand. The focus on older women, the self selected nature of participants, and the overall participation rate of $19.5 \%(1089 / 5913$ invited minus 317 returned to sender) might further limit the generalisability of results to younger women and to men. Of those assessed for eligibility, however, we excluded $47 \%$ as they were already physically active, which is in line with national data on physical activity levels. $^{\text {? }}$

The absence of a significant difference in secondary clinical end points is not surprising and might be partly due to the increase in overall physical activity in the control group. Therefore, while this sample size was large enough to detect quite small differences in physical activity between the groups, it was not large enough to detect as significant any differences in clinical outcomes. There is, however, a well established relation between increasing physical activity and health benefit, so showing a small increase across a population has health benefits and can be cost effective considering the low cost of the intervention. ${ }^{16}$

The use of a self reported measure as the main outcome is a potential weakness but, when validated against an objective measure, the physical activity questionnaire performed well. ${ }^{2425}$ Objective measures of physical activity, such as activity monitors, would have added to the validity of these findings. Adverse events of falls and injuries were also self reported so were open to recall bias.

Table 3 | Mean change ( $95 \%$ confidence interval) in quality of life outcomes in intervention and control groups from baseline to 12 and 24 months

\begin{tabular}{|c|c|c|c|c|c|}
\hline \multirow[b]{2}{*}{ SF-36 subscale } & \multicolumn{2}{|c|}{ Intervention } & \multicolumn{2}{|c|}{ Control } & \multirow[b]{2}{*}{ Pvalue* } \\
\hline & 12 months & 24 months & 12 months & 24 months & \\
\hline Physical function & 2.17 (1.12 to 3.21$)$ & $-0.09(-1.13$ to 0.94$)$ & $0.07(-0.97$ to 1.11$)$ & $-0.91(-1.94$ to 0.12$)$ & 0.03 \\
\hline Role physical & $-1.09(-2.80$ to 0.62$)$ & $-2.03(-3.84$ to -0.21$)$ & $1.64(-0.07$ to 3.35$)$ & $1.35(-0.47$ to 3.16$)$ & $<0.01$ \\
\hline Bodily pain & $-0.53(-2.56$ to 1.49$)$ & $-1.56(-3.67$ to 0.56$)$ & $0.28(-1.74$ to 2.30$)$ & $-0.40(-2.51$ to 1.71$)$ & 0.5 \\
\hline Vitality & 2.24 (1.33 to 3.15$)$ & $1.63(0.72$ to 2.54$)$ & 0.98 (0.09 to 1.87$)$ & 1.88 (0.97 to 2.78$)$ & 0.3 \\
\hline Social functioning & $1.21(-0.55$ to 2.97$)$ & $-1.14(-2.95$ to 0.66$)$ & $0.47(-1.27$ to 2.22$)$ & $0.16(-1.64$ to 1.96$)$ & 0.8 \\
\hline Role emotional & $1.28(-0.17$ to 2.72$)$ & 2.02 (0.59 to 3.45$)$ & $0.05(-1.40$ to 1.49$)$ & $0.73(-0.69$ to 2.16$)$ & 0.2 \\
\hline Mental health & $1.73(0.82$ to 2.63$)$ & $1.49(0.54$ to 2.44$)$ & $0.51(-0.39$ to 1.42$)$ & $0.39(-0.56$ to 1.34$)$ & $<0.05$ \\
\hline General health & 2.69 (1.54 to 3.84$)$ & $1.26(0.02$ to 2.51$)$ & 1.17 (0.03 to 2.32$)$ & $0.20(-1.05$ to 1.44$)$ & 0.09 \\
\hline
\end{tabular}

*Analyses took into account repeated measures and adjusted for baseline values. 


\section{WHAT IS ALREADY KNOWN ON THIS TOPIC}

Achieving 30 minutes of moderate intensity physical activity on five or more days a week is associated with a substantial reduction in the risk of many chronic diseases and improves quality of life

Secondary prevention studies have shown the effectiveness of programmes for reducing inactivity and chronic disease

Few primary prevention programmes have produced sustainable increases in physical activity

\section{WHAT THIS STUDY ADDS}

This programme of exercise on prescription increased physical activity and improved some variables of quality of life over two years

This finding supports the role of exercise on prescription programmes in reducing population levels of physical inactivity

There was a small increase in falls and injuries associated with the programme

\section{Conclusions}

Programmes of exercise on prescription can produce sustained increases in physical activity among less active middle aged and older women over two years. Furthermore, a second face to face session with prolonged monthly telephone support might improve the effectiveness of the current brief interventions delivered in primary health care. ${ }^{14}$ There is now widespread acceptance that an increase in physical activity to recommended levels has considerable health benefits, including an estimated $20-30 \%$ reduction in all cause mortality. ${ }^{13536}$ Therefore, reducing physical inactivity by $10 \%$ across a primary care population of less active adults could have considerable health impact.

Improving the modifiable risk factors of physical inactivity and obesity at a population level will require multiple measures including legislation, public health media messages, and environmental changes as well as dietary and physical activity programmes.

We thank the women who participated in this trial and the primary care practices from which participants were recruited.

Contributors: BAL was the principal investigator, conceived the study, and contributed to the study design and writing the paper. SBR, CRE, ACD, and AF were coinvestigators and all contributed to the study design. SBR was the project and data manager and performed preliminary data collation and formatting and contributed to writing the paper. CRE and SAM performed the data analyses and contributed to writing the paper. ACD and $A F$ contributed to the interpretation of results and the final draft of the paper. All authors read and approved the final version of the manuscript. Data collection and entry were performed by Selina Brown, Rita Neve, Alice Paul, Jane Bowers, Esther Sweet, and Lucetta Reid. The Kapiti branch of Sport Wellington Region (Helene Kay) provided the telephone counselling to study participants. BAL is guarantor.

Funding: This work was supported by the National Heart Foundation of New Zealand (grant number 1091 and grant-in-aid numbers 1091 and 1222), the Lottery Health Research Grants Board, the Hutt Valley District Health Board, Sport and Recreation New Zealand, and the Maori Health Directorate (Ministry of Health).

Ethical approval: This work was approved by the Central Region Ethics Committee (formerly the Wellington Ethics Committee) in September 2004 (WGT/04/08/061). Participants gave written informed consent to participate in this study.
Competing interests: None declared.

Provenance and peer review: Not commissioned; externally peer reviewed.

1 Chief Medical Officer. At least five a week: evidence on the impact of physical activity and its relationship to health: a report from the chief medical officer. London: Department of Health,

2004. www.dh.gov.uk/en/Publicationsandstatistics/Publications/ PublicationsPolicyAndGuidance/DH_4080994

2 Schulze MB, Hu FB. Primary prevention of diabetes: what can be done and how much can be prevented? Ann Rev Public Health 2005;26:445-67.

3 Hu FB, Stampfer MJ, Colditz GA, Ascherio A, Rexrode KM, Willett WC et al. Physical activity and risk of stroke in women. JAMA 2000;283:2961-7.

4 Colditz GA, Samplin-Salgado M, Ryan CT, Dart H, Fisher L, Tokuda A, et al. Harvard report on cancer prevention. Vol 5. Fulfilling the potential for cancer prevention: policy approaches. Cancer Causes Control 2002;13:199-212.

5 US Department of Health and Human Services. Physical activity and health: a report of the surgeon general. Atlanta GA: US Department of Health and Human Services, Centers for Disease Control and Prevention, National Center for Chronic Disease Prevention and Health Promotion, 1996.

6 Chaudhury M, Roth M. Physical activity. In: Craig R, Mindell J, eds. Cardiovascular disease and risk factors in adults. Vol 1. Health survey for England 2006. London: National Centre for Social Research, 2006:111.

7 Van Aalst I, Kazakov D, Mclean G. SPARC facts. Results of the New Zealand sport and physical activity surveys (1997-2001). Wellington, NZ: Sport and Recreation New Zealand, 2003.

8 Pan X, Li GW, Hu YH, Wang JX, Yang WY, An ZX, et al. Effects of diet and exercise in preventing NIDDM in people with impaired glucose tolerance. The Da Qing IGT and Diabetes Study. Diabetes Care 1997;20:537-44.

9 Knowler WC, Barrett-Connor E, Fowler SE, Hamman RF, Lachin JM, Walker EA, et al. Reduction in the incidence of type 2 diabetes with lifestyle intervention or metformin. N Engl J Med 2002;346:393-403.

10 Tuomilehto J, Lindstrom J, Eriksson JG, Valle T, Hamalainen $\mathrm{H}$, Ilanne-Parikka P, et al. Prevention of type 2 diabetes mellitus by changes in lifestyle among subjects with impaired glucose tolerance. N Engl/ Med 2001;344:1343-50.

11 Foster C, Hillsdon M, Thorogood M. Interventions for promoting physical activity. Cochrane Database Syst Rev 2005;(1):CD003180.

12 Sorensen JB, Skovgaard T, Puggaard L. Exercise on prescription in general practice: a systematic review. Scand J Prim Health Care 2006;24:69-74.

13 NICE. A rapid review of the effectiveness of exercise referral schemes to promote physical activity in adults. London: Public Health Collaborating Centre-Physical Activity, 2006. www.nice.org.uk/nicemedia/pdf/PA Exercise Referral Review Final May 2006.pdf

14 Elley CR, Kerse N, Arroll B, Robinson E. Effectiveness of counselling patients on physical activity in general practice: cluster randomised controlled trial. $B M / 2003 ; 326: 793$.

15 Elley R, Kerse N, Arroll B, Swinburn B, Ashton T, Robinson E. Costeffectiveness of physical activity counselling in general practice. $N Z$ Med J 2004;117:U1216.

16 Dalziel K, Segal L, Elley CR. Cost utility analysis of physical activity counselling in general practice. Aust N ZJ Public Health 2006;30:57-63.

17 Cook NR, Cohen J, Hebert PR, Taylor JO, Hennekens CH. Implications of small reductions in diastolic blood pressure for primary prevention. Arch Intern Med 1995;155:701-9.

18 Elley CR, Kerse NM, Arroll B. Why target sedentary adults in primary health care? Baseline results from the Waikato Heart, Health, and Activity Study. Prev Med 2003;37:342-8.

19 Rose SB, Elley CR, Lawton BA, Dowell AC. A single question reliably identifies physically inactive women in primary care. N Z Med) 2008;121:U2897.

20 Canadian Society for Exercise Physiology. Physical activity readiness questionnaire (PAR-O). 2002. www.csep.ca/main.cfm?cid=574\&nid $=5110$

21 Rose S, Lawton B, Dowell A, Fenton A. Risk factors for type 2 diabetes in postmenopausal New Zealand women: a cross-sectional study. $N Z$ Med J 2004;117:U1206.

22 Rose SB, Lawton BA, Elley CR, Dowell AC, Fenton AJ. The Women's Lifestyle Study, 2-year randomized controlled trial of physical activity counselling in primary health care: rationale and study design. $B M C$ Public Health 2007;7:166.

23 Craig CL, Marshall AL, Sjostrom M, Bauman AE, Booth ML, Ainsworth BE, et al. International physical activity questionnaire: 12 country reliability and validity. Med Sci Sports Exerc 2003;35:1381-95. 
24 McLean G, Tobias MI. The New Zealand physical activity questionnaires: report on the validation and use of the NZPAQ-LFand NZPAQ-SFself-report physical activity survey instruments. Wellington, New Zealand: Sport and Recreation New Zealand (SPARC), 2004. www.sparc.org.nz/research-policy/research/nzspas-97-01/ nzpaq

25 Moy K, McFarlane K, Scragg R, Robinson S. Validation of MOH-short and SPARC-long physical activity questionnaires: final report. Auckland: University of Auckland and Sport and Recreation New Zealand, 2003.

26 McHorney CA, Ware JE Jr, Raczek AE. The MOS 36-item short-form health survey (SF-36): II. Psychometric and clinical tests of validity in measuring physical and mental health constructs. Med Care 1993;31247-63.

27 Sport and Recreation New Zealand. The green prescription. 1997 www.sparc.org.nz/getting-active/green-prescription/overview.

28 Stevens W, Hillsdon M, Thorogood M, McArdle D. Cost-effectivenes of a primary care based physical activity intervention in 45-74 year old men and women: a randomised controlled trial. Br J Sports Med 1998;32:236-41.

29 Salmond C, Crampton P, Sutton F. NZDep91: a New Zealand index of deprivation. Aust N ZJ Public Health 1998;22:835-7.
30 Writing Group for the Activity Counselling Trial Research Group. Effects of physical activity counselling in primary care. JAMA 2001;286:677-87.

31 Kinmonth A-L, Wareham NJ, Hardeman W, Sutton S, Prevost AT, Fanshawe T, et al. Efficacy of a theory-based behavioural intervention to increase physical activity in an at-risk group in primary care (ProActive UK): a randomised trial. Lancet 2008;371:41-8.

32 Fox KR. The influence of physical activity on mental well-being. Public Health Nutr 1999;2:411-8.

33 Tsai J-C, Yang H-Y, Wang W-H, Hsieh M-H, Chen P-T, Kao C-C, et al. The beneficial effect of regular endurance exercise training on blood pressure and quality of life in patients with hypertension. Clin Exp Hypertens 2004;26:255-65.

34 New Zealand Sport and Recreation New Zealand (SPARC). What are "green prescriptions" (GRx). Wellington: SPARC, 2008.

35 Lee IM, Skerrett PJ. Physical activity and all-cause mortality: what is the dose-response relation? Med Sci Sports Exerc 2001;33(6 suppl):S459-71; S493-4

36 Warburton DER, Nicol CW, Bredin SSD. Health benefits of physical activity: the evidence. CMAI 2006;174:801-9.

Accepted: 29 September 2008 